\title{
ALGUNOS COMENTARIOS SOBRE EL DERECHO PRIVILEGIADO LOCAL DE LLÍVIA
}

\author{
José Manuel Pérez-Prendes MuÑoz-Arraco \\ Departamento de Historia del Derecho y de las Instituciones \\ Facultad de Derecho de la Universidad Complutense de Madrid \\ jmpprendes@telefonica.net \\ Al profesor don Josep Maria Font i Rius \\ en su centenario
}

Evidentes son los títulos generales de admiración y respeto que obligan a todos los profesionales de la Historia del Derecho con el profesor Font i Rius y dan razón de ser a los merecidos homenajes que se la han tributado con ocasión de haber llegado lúcido y trabajador constante a cumplir los cien años de vida. Mas a eso hay que añadir, en mi caso, un vínculo personal de afecto y gratitud que acrecienta y personaliza tal relación ${ }^{1}$.

Me ha parecido oportuno elegir para la ocasión un tema relacionado con la historia del Derecho local y específicamente la catalana. En ese marco existe una pieza jurídica, el llamado Llibre ferrat, un cartulario que recopila selectivamente privilegios dirigidos por diversos monarcas y otras autoridades a la localidad de Llívia, la antigua Iulia Lybica, municipio de Derecho latino y cabeza del pagus liviensis. A esa fuente voy a referirme aquí, con unas simples notas orientadas hacia una triple temática: enuclear en el tiempo la masa normativa básica del Derecho privilegiado de Llívia; señalar su hilo cronológico conductor y explanar la posibilidad de sugerir alguna hipótesis explicativa sobre el criterio que pudo guiar la confección del cartulario.

${ }^{1}$ Le debo un especial reconocimiento por haber recogido hace algunos años en la revista Índice bistórico español, de la Universidad de Barcelona, diversos resúmenes y comentarios de mis publicaciones. Con ello se constituyó, consciente y generosamente, en significativa y continuada excepción que reprobaba tácita, pero claramente, la línea de conducta que ordenaba ignorar o menospreciar cuanto yo pudiese escribir, actitud inspirada por Alfonso García-Gallo y seguida con denuedo por la mayoría de sus discípulos. 


\section{EL LLIBRE FERRAT DE LLÍVIA. EDICIONES DE SU TEXTO}

Aunque se extiende desde Ramón Berenguer IV hasta el siglo XVIII, el Derecho privilegiado local de Llívia ha sido olvidado o ignorado por textos clásicos como el de Andreu Bosch ${ }^{2}$. Creo poder afirmar que la introducción de su pieza más representativa, el Llibre ferrat (en adelante $L f$ ) se hizo por primera vez en las menciones que hice de ella en las diversas ediciones de mi Curso de Historia del Derecho español ${ }^{3}$. Pero la primera publicación íntegra de ese cartulario se debe inequívocamente a don Ramón Fernández de Tirso y Samper. Incluyó este autor una transcripción completa del texto del cartulario en cuestión, en su tesis doctoral, leída en la Facultad de Derecho de la Universidad de Granada en 1974. Posteriormente (1984) la publicó como libro, editado por la Universidad de Alicante. Allí se contenía por entero tanto la regesta titulada «Taula del presente llibre» (con quince entradas, sin numerar) como todas y cada una de las diferentes piezas documentales que forman el $L f^{4}$.

Justo al año siguiente, Dom Cebrià Baraut i Obiols, OSB, ilustre paleógrafo, bien conocido descubridor y editor de documentos medievales ${ }^{5}$, reproducía el contenido del $L f$, añadiendo un comentario propio y adicio-

2 A. Bosch, Summari, index o epitome dels admirables y nobilissims titols de bonor de Cathalunya, Rosselló, y Cerdanya y de les gracies, privilegis, prerrogatiues, preheminencies, llibertats e inmunitats gosan segons les propies, y naturals lleys, Perpiñán, Estamper Pere Lacauallería, 1628. Menciona abundantemente textos relativos a La Cerdanya, pero nunca cita a Llívia. Cfr. el enlace bttp://books.google.es/books?id=X99FAAAAcAAJEprintsec=fro

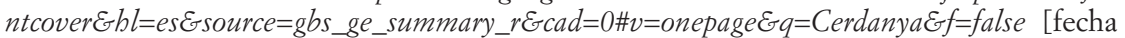
de la consulta: 1 de marzo de 2015].

${ }^{3}$ La última es de 2004, Madrid, UCM. Yo había conocido y manejado el Lf durante mis estancias en Puigcerdà, en los veranos de 1962 y 1963, cuando realizaba allí las prácticas de la IPS en el regimiento de cazadores de montaña «Alba de Tormes» 36, de la División de Infantería «Urgel» 42.

${ }^{4}$ Ramón FernándeZ De Tirso y SAmper, El Llibre ferrat de Llívia, Alicante, Secretariado de Publicaciones de la Universidad de Alicante, 1984. Existe un ejemplar en la Biblioteca Nacional de Madrid. Al dar a la imprenta su trabajo no tomó en cuenta los consejos que le dimos los miembros del tribunal de su tesis para suprimir o corregir siquiera cuanto perjudicaba la virtud de ser la primera edición documental del Llibre. Ese aspecto fue el que juzgamos positivo, pero lo desmañado de la bibliografía y lo elemental del comentario jurídico justificó la escueta calificación de «notable» recibida.

5 Puede consultarse la necrología debida a J. Morán i Ocerinjauregi del Institut d'Estudis Catalans. En ella se resalta con justicia la gran calidad de paleógrafo y la continuada dedicación a la investigación como rasgos definitorios del insigne benedictino. En un plano diferente queda su valor como diplomatista y desde luego no se puede esperar demasiada sensibilidad jurídica en sus textos. 
nándole con otros documentos, ésos sí, no publicados o no muy conocidos hasta entonces. Pero todo ello sin citar para nada ni la tesis ni el libro de Fernández de Tirso ${ }^{6}$, ni siquiera en la amplia parte en la cual coincidía plenamente con él, es decir en la transcripción del cartulario.

Los objetivos científicos perseguidos por Baraut eran realmente dos. El primero, la presentación del contenido del $L f$, algo que, de hecho, no encerraba descubrimiento ninguno ${ }^{7}$. El segundo, ése sí nuevo, era completar por vía doble ${ }^{8}$ la información reunida en tal colección documental:

«D'una banda hom s'adona que les mercès fetes pels reis [...] a Llivia comencen molt abans del segle XIV [...] d'altra banda [...] d'afegir-hi altres notícies desconegudes o preterides per l'autor d'aquella compilaciò».

Digo que lo realmente novedoso era lo indicado en la segunda de esas dos frases suyas, pues ciertamente ya en la edición de Fernández de Tirso se podía advertir que en los textos reunidos en el $L f$ se confirmaban otros más antiguos, luego era perfectamente posible apelar a ellos para sostener que los privilegios reales habían comenzado, en efecto, a otorgarse a Llívia bastante antes de finales del siglo XIV. El esfuerzo de Baraut cobra pues su mayor valor cuando acude a libros y repositorios diferentes para reunir una notable legislación complementaria que $L f$ desechó por razones que no pueden hoy establecerse con certeza. A eso debo añadir para dejar este aspecto que, si los análisis jurídicos de contenido que ambos ensayaron resultan elementales, encierra más calidad el de Baraut que el de Fernández de Tirso.

\section{SOBRE EL CONTENIDO REAL DEL LF}

Como puede verse en las transcripciones este cartulario ${ }^{9}$, hechas tanto por uno como por otro de ambos editores, el $L f$ pretende ordenar, de

${ }^{6}$ C. Baraut, El Llibre ferrat. Privilegis y Ordinacions de la Vila de Llívia, Patronat del Museu de Llívia, obradors del Monestir de Sancta María de Montserrat, 1985.

7 Escribo «de hecho» por estar claro que no lo afirma expresamente, pero lo cierto es que ya estaba publicado el Llibre por Fernández de Tirso, como he documentado arriba. Por otra parte, las diferencias que pueden apreciarse entre las dos transcripciones del cartulario no son conceptualmente significativas. Lo más que se puede observar es una mayor pulcritud paleográfica de detalles en el texto de Baraut, cosa natural dado lo que indico supra, nota 5 .

${ }^{8}$ C. BARAUT, El Llibre ferrat..., op. cit., p. 66.

9 No me voy a detener en su descripción documental, tarea ya realizada en las ediciones 
forma desde luego no cronológica, quince documentos dotados de autoridad regia desde 1387 hasta 1579, a los que añade después dos sentencias. Una, de la que dice Baraut haber sido dictada en 1358, de Francesc de Sagarraga, lugarteniente de gobernador de los condados de Rosselló y de La Cerdanya ${ }^{10}$. Otra, del visitador regio del Principado y esos condados, dictada en $1613^{11}$. Pero las cosas no son tan sencillas como parecen resultar de los trabajos de ambos editores.

Para empezar, las noticias que se aportan en la «Taula» inicial ni siempre son exactas, ni en ellas se hace otra cosa que un examen muy escueto de la forma y el contenido de una parte de los preceptos recogidos. Es de justicia señalar que en el trabajo de Baraut, además de reproducir y corregir algunos errores de esa «Taula», se incluyen otras regestas ${ }^{12}$.

En primer lugar, ya he dicho aquí que hay recogidos en el $L f$ (aunque sea por vía indirecta) más textos que esos diecisiete que en definitiva se suman en él, pues resulta que hay hasta veinticinco textos documentados. En efecto, en varios de los privilegios regios y también en la llamada «Sentencia de Sagarriga», se incluyen otros preceptos reales anteriores, con la intención de pedir sean confirmarlos, cosa que los monarcas hacen en todos ellos. Ni Fernández de Tirso ni Baraut hicieron la menor mención de los documentos que se copian por los otorgantes para confirmarlos y tampoco dijeron nada sobre la posibilidad de ir en esa cronología algo más lejos de lo directamente perceptible en una primera lectura del $L f$. Pero resulta que, considerándolos, la configuración de la masa normativa a contemplar realmente se hace superior. Como la mayoría de tales confirmaciones reproducen los textos verificados y no se limitan a citarlos, no hay más remedio que admitir la certeza de esa ampliación de la masa legislativa.

En segundo lugar resulta también que, sin salir de los límites del propio $L f$, la cronología (1387-1613) de los textos llivienses incluidos en él debe ser rectificada para llevarla prácticamente hasta un siglo antes, esto es, desde 1289, pese a lo establecido por ambos editores, que sólo copiaron la fijada por el redactor del $L f$, es decir, 1387. Eso sólo por lo que al

de R. Fernández de Tirso y C. Baraut. En la «Taula» inicial se hace un índice de la documentación reunida no demasiado exacto, que $\mathrm{C}$. Baraut corrige al transcribirla.

${ }^{10}$ En realidad, enviada por él a su superior para que la mandara ejecutar, como veremos. El ponente autor del texto fue un juez comisionado llamado Berenguer de Isernia.

${ }^{11}$ Ésta no figura en la «Taula», parece ser un error o quizá se añadió después.

${ }_{12}$ Discreparé más abajo de alguna de ellas, como la que antepone a $L f$ núm. 16 , pero se trata de comentarios de detalle. 
cartulario mismo se refiere, sin contar por ahora que, como veremos más adelante, en realidad el comienzo documentable del Derecho lliviense nos lleva al siglo XII.

\section{RECONSTRUCCIÓN DE LAS FUENTES DEL DERECHO PRIVILEGIADO LOCAL DE LLÍVIA, A PARTIR DE LOS DATOS DEL $L F$}

Según descubre una mínima palingenesia del $L f$, se puede decir con seguridad que la perspectiva del Derecho lliviense que deseó asegurar ese cartulario viene soportada, tanto explícita como implícitamente (esa dualidad es muy importante), en los contenidos normativos de unas piezas documentales en realidad más numerosas que las presentadas en él a primera vista.

En efecto, se distinguen en el $L f$ dos tipos de fuentes. Uno esta formado por textos patentes o explícitos y es el más numeroso. En segundo lugar aparecen otros, menores en número, que son copiados o aludidos en los anteriores y, por tanto, están implícitos en ellos. Los primeros son los presentados con números en las transcripciones arriba citadas del $L f$. Los segundos no han sido individualizados en tales transcripciones como es lógico, pues al transcribir se debe respetar la personalidad de lo transcrito. Podía, sin embargo, haberse introducido alguna nota o comentario destacando su presencia, pero no se ha hecho. Así que han quedado inmersos en los patentes o explícitos y me parecido necesario aislarlos lo más claramente posible de ese marco para distinguirlos bien.

Trataré aquí de reconstruir a continuación el conjunto general que se forma con ambos elementos, explícitos e implícitos. Para ello ordeno cronológicamente su serie. Al hacerlo señalo con letras cada factor documental contemplado, tanto si es explícito, como si es implícito. Advierto al lector que, como muchas de las piezas que he identificado con letras, no están individualizadas en las transcripciones del $L f$, procuro orientarle siempre hacia las cifras de éstas que permiten localizar lo más rápidamente posible el punto del cartulario donde se encuentran colocadas:

A) 1289: Jaime II de Mallorca, Perpiñán, reproducido (en adelante rep.) en $L f$ núm. 4. Reduce al diezmo de la décima parte (retrodecima) las costas a pagar en los pleitos por deudas, para los llivienses domiciliados y contribuyentes en el mantenimiento del castillo. 
B) 1337: Jaime III de Mallorca, Palma de Mallorca, rep. en $L f$ núm. 16. De acuerdo con el Derecho consuetudinario (sicut antiquis temporibus fuit observatum), el juez de La Cerdanya debe acudir a Llívia para tomar testimonios y realizar y sentenciar los pleitos suscitados entre llivienses, pese a haber caído esa regla en desuso.

C) 1342: Constanza de Aragón, esposa de Jaime III, rep., en $L f$ núm. 16. Vista la disposición anterior de Jaime III, de la cual había recurrido el procurador real con la oposición de los representantes de Llívia, la reina ordena el cumplimiento del mandato del rey Jaime.

D) 1342: Jaime III, en el castillo de Évol ${ }^{13}$, rep. en $L f$ núm. 16 . El rey informa al vicario de La Cerdanya que los representantes de Llívia, al solicitar lo dispuesto por el monarca sobre la administración de justicia en 1337 [doc. B)], habían probado otras muchas normas anteriores, regias y de Derecho consuetudinario que deseaban ver restauradas y a cuya puesta en práctica se resistía el vicario, so pretexto de que no se mencionaban en el privilegio de 1337. El monarca ordena su cumplimiento por considerar que han sido suficientemente probadas.

E) 1355: Francesc de Sagarriga, lugarteniente del Gobernador, Guillem de Bellera, Perpiñán, rep. en $L f$ núm. 16. Mandato de cumplimiento de lo preceptuado por la reina Constanza en el doc. C). Da de cuenta de las actuaciones al gobernador para que se mandase ejecutar lo sentenciado e inserta los docs. B), C) y D).

F) 1358: Sentencia de Berenguer de Iserna, juez del patrimonio regio, sobre el contencioso suscitado entre las ciudades de Puigcerdà y Llívia, a partir de la disposición de Jaime III en 1337, rep. en Lf núm. 16 [docs. B) a E)]. Fue mandada por el citado lugarteniente Francesc de Sagarriga el 26 de enero de ese año, después de informado el juez, a Guillem de Bellera, para que mandase ejecutar.

En este complejo documento, el citado Sagarriga realiza las siguientes actuaciones:

1) Informar al gobernador, Guillem de Bellera, de haber recibido tanto unas copias de los privilegios de los reyes Jaime III y Constanza que transcribe [son los aquí reseñados con las letras B) a E)] y que le han sido enviadas por la ciudad de Llívia; como unas cartas del dicho gobernador

${ }^{3}$ C. López Rodríguez, Liber Patromonii regii Valentiae, Valencia, Universidad de Valencia, 2006, p. 401. 
acerca del pleito sobre tales privilegios, existente entre las ciudades de Puigcerdà y Llívia.

2) Darle cuenta, inmediatamente después, de que ha reunido en pleno a sus consejeros y se ha acordado, en virtud de la aplicación del Derecho territorial (Constituciones generales de Cataluña), la inmediata aplicación del privilegio de la reina Constanza, que aquí he marcado con la letra E).

3) Haber encargado al «discreto» [sic] Berenguer de Iserna, jurisperito de Perpiñán, que redactara la sentencia en el pleito indicado, cosa que éste concluyó el 26 de enero del año citado en la misma ciudad.

4) Haber cuidado además que Isernia supervisase la redacción que se iba a hacer oficial (vidit Berengarius).

De la redacción que copia el $L f$ se deduce que Sagarriga remitió todo lo así actuado al gobernador Bellera, de modo que la sentencia no puede atribuírsele de ningún modo ${ }^{14}$, pues en cuanto su texto material pertenece a Isernia y en cuanto a su ejecución correspondería a Bellera. Lo que parece resultar de todo es que esa ejecución o no se produjo o fue recurrida, pues el $L f 16$ (in fine) recoge ecos del asunto todavía en el año $1604^{15}$.

La Sentencia de Isernia estimó cinco fundamentos de Derecho: a) existencia del Derecho consuetudinario alegado para que el juez de La Cerdanya se desplazara a Llívia en los términos indicados; $b$ ) práctica de remitir a Llívia el reo lliviense que era detenido en Puigcerdà; c) práctica de traslado a Llívia del juez competente para abrir audiencia, si algún lliviense era parte, tanto en lo penal como en lo civil e incluso en litigios sobre contratos verbales; $d$ ) práctica de ejecución en Llívia de sentencias penales dictadas contra llivienses, y e) incompetencia del vicario de La Cerdanya para personarse contra la disposición de Jaime III de 1337 [doc. E)]. Señaló tres considerandos: a) el tenor de las disposiciones regias sobre las que se actuaba y el de lo probado por la parte de Llívia; b) que la ciudad de Puigcerdà no había introducido otras razones que las alegadas hasta la realización de este juicio, y c) que era de aplicación el principio establecido en la legislación territorial (en este caso las Constituciones generales de Cataluña) según el cual los juicios de la vicaría deben realizarse en el territorio apropiado y, por tanto, en el de la bailía. Por todo lo cual, sentenció a favor de las pretensiones llivienses el 26 de enero de 1358.

\footnotetext{
${ }_{14}$ Así lo sostiene C. Baraut, El Llibre ferrat..., op. cit., p. 58.

${ }^{15}$ Al final de $L f$ núm. 16 y con fecha de 1604 se insertan los testimonios de unas diligencias realizadas para la copia de todos los textos recogidos en ese documento del $L f$.
} 
G) 1375: Pedro IV (III) en Lleida, dos docs., de 5 de mayo y de 5 de junio, rep. en $L f$ núm. 4.

a) El primero (Lleida, 5 de mayo) inserta y confirma el doc. A) (Jaime III, 1289) sobre la reducción fiscal a la retrodécima y sus condiciones, reduciendo además los plazos durante los cuales podía recaudarse.

b) El segundo (Lleida, 5 de junio) se refiere al mismo tema, ampliando por iguales motivos las reducciones y supuestos de exigencia a los llivienses de prestaciones como las llamadas «opera», «guaytas» y «badas» ${ }^{16}$.

H) 1382: Pedro IV (III), Valencia, rep. en $L f$ núm. 6. Estima favorablemente la petición de los ciudadanos de Llívia contra las prácticas realizadas en algunos titulares de albergues, tierras y posesiones en la ciudad, pero no residentes en ella, para no cumplir las prestaciones que los dichos ciudadanos sí asumían.

I) 1387: Juan I, Barcelona, rep. en $L f$ núm. 1. Establece una línea de continuidad en el espíritu inspirador de la legislación regia referida a Llívia, mencionando nominalmente a los reyes Jaime (atavum), Pedro (abavum), Alfonso (patruum magnum), Jaime (proavum), Alfonso (avum), Pedro (patrem) y el propio monarca otorgante. A continuación la confirma por entero en todas las posibles clases de normas reales en las que se contuviera, juntamente con el Derecho consuetudinario y establece garantías penales contra su inaplicación o inobservancia.

J) 1405: Martín, Barcelona, rep. en $L f$ núm. 2. Insiste en la línea de continuidad citada y de nuevo confirma el Derecho privilegiado local de Llívia, pero haciendo especial preferencia, respecto e texto anterior del Derecho consuetudinario, que ahora es mencionado en primer lugar y separadamente, de forma que queda claro que esa categoría normativa es algo distinto a la aplicación consuetudinaria que consolidaba los textos regios, matiz que no quedaba tan claro en el documento anterior, donde la cita de lo consuetudinario era perfectamente interpretable en ese solo sentido.

K) 1413: Fernando I, Barcelona, rep. en $L f$ núm. 3. La conciencia de continuidad regia respecto de su actitud acerca del Derecho lliviense se conserva también, pero diluida. Más bien parecen menciones dirigidas a

${ }_{16}$ Sobre estas figuras cfr. los trabajos de P. Gifre Ribas, especialmente los accesibles en los enlaces http://dugi-doc.udg.edu/bitstream/handle/10256/4952/tpgr1de1.pdf?sequence $=1$ y http://www.raco.cat/index.php/Recerques/article/viewFile/137727/241553 (fecha de consulta: 3 de marzo de 2015). 
mostrar el vínculo personal y familiar del Trastámara con sus inmediatos predecesores, pues sólo se menciona a Pedro IV (III) (avum), a sus predecesores en general, a Martín (avunculum) y, separadamente de esa enumeración, a Juan I (avunculum). La parte dispositiva presenta los mismos rasgos señalados en el texto anterior.

L) 1447: 4 de febrero, María (lugarteniente general de Alfonso V) Barcelona, rep. en $L f$ núm. 8. Otorga a los llivienses un salvoconducto general ante las autoridades de La Cerdanya contra la responsabilidad que pudiera ser ejecutable judicialmente sobre sus bienes inmuebles, muebles y semovientes a causa de delitos o deudas ajenas si no habían asumido la cualidad de fiadores en algún grado y en cualquier caso nunca antes de dictarse una sentencia firme (de directo) fundamentada racionalmente en Derecho (ius et ratio).

M) 1447: 6 de febrero, María, Perpiñán, rep. en $L f$ núm. 9. Señalamiento de un plazo de quince años ${ }^{17}$ para que el concejo imponga gravámenes sobre pan, vino, carne y otras mercaderías o servicios habitualmente comercializadas (incluso en arrendamientos) en la ciudad y su término, satisfaciendo así las obras de conservación y reparación del castillo. Una quinta parte podría ser invertida en pagar deudas municipales, bajo el control del tesorero regio y su delegado.

N) 1447: 6 de febrero, María, Barcelona, rep. en $L f$ núm. 10. Restauración del Derecho consuetudinario lliviense a pasturar en Estavar, Bajanda y Ro, que había sido usurpado por la fuerza por el vizconde de Èvol, dando a éste plazo para recurrir ante el vicario de La Cerdanya.

O) 1449: 1 de febrero, María, Perpiñán, rep. en $L f$ núm. 5. Exención a los llivienses de responsabilidad por los delitos cometidos por bandidos que se hubieran refugiado en su término, si los nombres de tales malhechores no hubieran sido pregonados públicamente por las autoridades de La Cerdanya en el territorio de Llívia.

P) 1449: 1 de febrero, María, Perpiñan, rep. en $L f$ núm. 6. Incluye y confirma el doc. $\mathrm{H}$ ).

Q) 1449: 14 de febrero, María, Perpiñán, rep. en $L f$ núm. 7. Confirma, sin reproducirlos ni fecharlos, los privilegios otorgados por Pedro IV (III), Juan I y Martín, que eximían a Llívia del pago de lezda en el Rosse-

${ }_{17}$ Curiosamente, pese al tecnicismo que se advierte en estos documentos, no se usa el término indictio como parece propio, dado el ambiente y los redactores, juristas casi siempre dotados de títulos académicos nada despreciables. 
lló y La Cerdanya, a causa de la carga que suponía la custodia especial del castillo y el monte.

R) 1450: 1 de febrero, María, Perpiñan, rep. en $L f$ núm. 4. Incluye y confirma los tres documentos aquí reseñados en las letras A) y G).

S) 1493: Fernando II, Perpiñán, rep. en $L f$ núm. 12. Autorización al concejo lliviense para la construcción de un «orreo» (vulgariter dicitur graner) destinado a ser almacén donde se conserve, administre y distribuya el trigo (sive blada). El baiulus de Llívia deberá dar cuenta trienal de la gestión realizada ante los jueces de plantilla de la vicaría de Puigcerdà, conforme lo dispone el Derecho territorial (Constituciones del Principado de Cataluña).

T) 1525: Carlos I, Madrid, rep. en $L f$ núm. 11. Transcribe y confirma el doc. S).

U) 1528: Carlos I, Monzón, rep. en $L f$ núm. 13. Confirmación y nueva concesión general del Derecho privilegiado local de Llívia, planteada con intención exhaustiva de forma y contenido todos y cada uno de los privilegios, franquezas, cartas, inmunidades, exenciones, costumbres, ordenanzas, y buenos usos, escritos(as) o no.

V) 1529: Carlos I, Barcelona, rep. en $L f$ núm. 14. Declaración y orden de tutela (dirigida a todas las autoridades del Rosselló y La Cerdanya) del derecho lliviense a pasturar y aprovechar la pradera natural de Estavar (marcando sus términos geográficos), en aplicación del principio reconocido por el Derecho territorial (Constituciones de Cataluña) que prohíbe de la posesión, si no existe sentencia que lo ordene. La decisión regia se toma amparada en un examen técnico realizado por Juan Simó, bachiller en Derecho, juez ordinario de la vicaría de La Cerdanya y su lugarteniente, Gaspar de Soldevila, doctor en Derecho civil y canónico.

W) 1579: Fernando de Toledo, virrey (Felipe II) Barcelona, rep. en $L f$ núm. 15. Aprobación y puesta en vigor de las normas para elección y régimen jurídico de los cargos municipales en Llívia, Cereja y Gurguja, según la pesquisa realizada para determinar el Derecho consuetudinario al respecto (consuetuts retingudes en la memoria dels qui han habitat). Consiste en un total de catorce capítulos, que el virrey ordena respetar y ejecutar a todas las autoridades.

X) 1604: Certificación de los notarios Lorenzo Benito Puig y Montserrat Bordo, rep. en $L f$ núm. 16. Solicitada por Francisco de Maranges, cónsul de Llívia, y Juan de Maranges, doctor en ambos Derechos, y juez 
ordinario de La Cerdanya. Se refiere a la documentación pertinente a la sentencia de Berenguer de Iserna, cfr. supra, doc. letra F).

Y) 1613: Josep Pérez de Bonyatos, visitador del Principado, bajo Felipe IV, rep. en $L f$ núm. 17. Sentencia (en rebeldía) de indemnización del doble de lo sustraído a la ciudad de Llívia y de posterior muerte en la horca, dictada contra Joan Costa, lugarteniente del batlle de Llívia, por varios delitos, especialmente los de abusos deshonestos y violación de la doncella María Alsina a la que se le ordena indemnizar con cien libras. Se absuelve por falta de pruebas a Jeroni Costa, notario de la bailía de Llívia, acusado de exigir pagos indebidos. Su inclusión algo extemporánea pudiera deberse a la intención de manifestar la vigencia de lo señalado en el fundamento de Derecho b) referido en la Sentencia de Isernia [cfr. supra, doc. F), punto 4].

\section{LA SERIE CRONOLÓGICA DEL DERECHO LLIVIENSE}

Como ya he indicado arriba, el valor principal del trabajo de Cebrià Baraut es la adición y publicación de treinta y ocho piezas del corpus del Derecho privilegiado local de Llívia, muchas de ellas no contempladas por el $L f$. Se trata de fuentes que o habían sido publicadas o citadas por otros autores, o se encontraban inéditas en varias sedes, concretamente: el archivo municipal de la misma villa y el de la Corona de Aragón ${ }^{18}$. Del mismo modo que el investigador citado actuó respecto del $L f$, tampoco se propuso enuclear los contenidos existentes en la documentación que aportó, un elemento primario, esto es, el hilo cronológico conductor de ese Derecho.

Intentaré trazarlo a continuación, mas, para hacer tal cosa, no basta con sumar sin más los datos que Baraut aportó con la serie establecida aquí en el punto anterior, al extraer los datos existentes en el $L f$. Es obligado tener en cuenta varios aspectos como: considerar aquellos contenidos, contemplar las duplicaciones con el $L f$, y observar que en los documentos nuevamente colacionados por Baraut hay referencias que él no individualiza, y otras que pueden ser descartadas desde el punto de vista de la fuerza de creación del Derecho, etcétera.

Aplicando esos matices, creo que la serie cronológica general a la que aludo quedaría establecida del modo siguiente, según los documentos hasta ahora conocidos, incluyendo el $L f$ y la legislación ajena a él:

${ }^{18}$ C. Baraut, El Llibre ferrat..., op. cit., pp. 26 y ss. 
1) s/f (s. XII), Ramón Berenguer IV de Barcelona, no conservado [cfr. Apèndix, C. Baraut, p. 66) ${ }^{19}$.

2) s/f (s. XII), Alfonso I, no conservado, confirma el anterior ( $A p$. CB, p. 66) ${ }^{20}$.

3) 1206, Pedro, abad del Monasterio de San Juan de las Abadesas, en cuanto procurador regio $\left(A p\right.$. CB, p. 65) ${ }^{21}$.

4) 1247, Jaime I, Teruel, confirmando sin copiarlos los docs. 1 y 2 de esta serie $(A p$. CB, p. 66) 22 .

3) 1257 , Jaime I, Lleida (Ap. CB, p. 67 ${ }^{23}$.

4) 1263, Jaime I, Tamarit (Ap. CB, p. 67 ${ }^{24}$.

5) 1268, Jaime I, Tarragona (Ap. CB, p. 68) 25

6) 1289, Jaime II de Mallorca, Perpiñán [doc. citado aquí como A), rep. en $L f$ núm. 4$]^{26}$.

7) 1289, Jaime II de Mallorca, Perpiñán (Ap. CB, p. 69) ${ }^{27}$.

8) 1298, Jaime II de Mallorca, s/1 (Ap. CB, pp.69-70) ${ }^{28}$.

9) 1304 Jaime II de Mallorca. Ribesaltes (Ap. CB, p. 70) ${ }^{29}$.

10) 1337, Jaime III de Mallorca [¿Palma de?] Mallorca [doc. citado aquí como B), rep. en $L f$ núm. $\left.16^{30}\right]$.

11) 1342, Constanza de Mallorca, Perpiñán [doc. citado aquí como C), rep. en $L f$ núm. 16$]^{31}$.

12) 1342, Jaime III de Mallorca, Évol [doc. citado aquí como D), rep. en $L f$ núm. 16] ${ }^{32}$.

${ }_{19}$ Es el doc. 2 en la numeración que Baraut da en su Apèndix. Existen otros casos similares que mencionaré uno a uno a continuación. Para no causar dudas con la serie numerada que ofrezco arriba, cito sólo en el cuerpo de este trabajo la página del trabajo de Baraut en la que se encuentra el dato o documento que recojo y remito a notas al pie el número del documento que Baraut da en su Apèndix, precedido siempre de la sigla CB para la oportuna identificación.

${ }^{20} \mathrm{CB}$ núm. 2.

${ }^{21}$ CB núm. 1.

${ }^{22}$ CB núm. 2.

${ }^{23}$ CB núm. 3.

${ }^{24}$ CB núm. 4.

${ }^{25}$ CB núm. 5.

${ }^{26}$ Cfr. supra, punto 3 de este trabajo.

27 CB núm. 7.

28 Baraut señala como fecha $1298-1330$, por estar recogido el privilegio del rey en una Sentencia de 1300. Es el núm. 8 de su Apèndix.

${ }^{29}$ CB núm. 9.

${ }^{30}$ Cfr. supra, punto 3 de este trabajo. CB núm. 10.

${ }^{31} \mathrm{CB}$ núm. 11.

${ }^{32}$ CB núm. 12. 
13) 1343, Jaime II de Mallorca, Perpiñán (Ap. CB, p. 72) $)^{33}$.

14) 1351, Pedro IV (III), Perpiñán (Ap. CB, p. 74) ${ }^{34}$.

15) 1352, Pedro IV (III), confirma el privilegio de Jaime III de 1343 (Ap. CB, p. 73) ${ }^{35}$.

16) 1353 , Pedro IV (III), Barcelona (Ap. CB, p. 75) ${ }^{36}$.

17) 1355, Francesc de Sagarriga, lugarteniente del gobernador, Guillem de Bellera, Perpiñán [doc. citado aquí como E), rep. en Lf núm. 16] ${ }^{37}$.

18) 1358, Sentencia de Berenguer de Iserna, juez del patrimonio regio $[$ doc. citado aquí como $\mathrm{F})]^{38}$.

19) 1360, Pedro IV (III), Zaragoza (Ap. CB, p. 75) ${ }^{39}$.

20) 1362, Pedro IV (III), Perpiñán (Ap. CB, p. 76) ${ }^{40}$.

21) 1364, Pedro IV (III), Zaragoza (Ap. CB, p. 77) ${ }^{41}$.

22) 1371, Infante don Juan, hijo de Pedro IV (III), Perpiñán (Ap. CB, p. 78$)^{42}$.

23) 1375, Pedro IV (III), Lleida [conjunto de dos docs. citados aquí como pieza $G)^{43}$, reps. en $L f$ núm. 4].

24) 1379 (18 de enero), Pedro IV (III), Barcelona (Ap. CB, p. 87) ${ }^{44}$.

25) 1379 (1 de abril), Pedro IV (III), Barcelona (Ap. CB, p. 88) ${ }^{45}$.

26) 1381, Pedro IV (III), Zaragoza reservándose sentenciar una reclamación de Llívia.

33 CB núm. 13.

${ }^{34} \mathrm{CB}$ núm. 14.

35 De nuevo, CB núm. 13.

${ }^{36}$ En este caso (no lo hace siempre) CB extrapola esta noticia de un texto posterior, cfr. CB núm. 15.

${ }^{37}$ Cfr. supra, punto 3 de este trabajo.

${ }^{38}$ Ibid.

${ }^{39} \mathrm{CB}$ núm. 16.

40 CB núm. 17.

${ }^{41}$ CB núm. 18.

${ }^{42}$ CB núm. 19.

${ }^{43}$ Cfr. supra, punto 3 de este trabajo. Baraut incluye con los núm. 22 y 23 de su Apèndix otros textos del mismo monarca, relacionados íntimamente entre sí, pero que primordialmente se refieren a los habitantes de Oceja y Puigcerdà. También existe una sentencia sobre ese tema dada por el rey Martín en 1397 (se menciona en otra posterior de la reina María, cfr. infra, doc. núm. 42). Todo ello tiene que ver con las decisiones de 1375 por parte de Pedro IV (III), pero dejando eso aparte, lo que interesa aquí es que, en realidad, las tres piezas son análogas, pero Baraut da valor como fuente del Derecho de Llívia a las dos primeras y no a la tercera. Yo entiendo que ese valor es igualmente lateral en las tres y, por tanto, no los incluyo en esta serie.

${ }^{44}$ CB núm. 24.

${ }^{45}$ CB núm. 25. 
27) 1382, Pedro IV (III), ratificando la sentencia, favorable a Llívia, en el tema anterior ${ }^{46}$.

28) 1382, Pedro IV (III), Valencia [en la misma fecha del documento anterior pero de contenido diferente, cfr. doc. citado aquí como $\mathrm{H})^{47}$, rep. en $L f$, núm. 6].

29) 1387, Juan I, Barcelona [doc. citado aquí como I) ${ }^{48}$, rep. en $L f$ núm. 1].

30) 1390, Juan I, Barcelona (Ap. CB, p. 91)

31) 1396, Juan I, Perpiñán $(A p . C B, \text { p. } 94)^{50}$.

32) 1405 (9 de mayo), Martín, Barcelona [cfr. doc. citado aquí como J) ${ }^{51}$, rep. en $L f$ núm. 2].

34) 1405 (12 de junio), Martín, Barcelona (Ap. CB, p. 95 $)^{52}$.

35) 1408, Martín, s/1 (Ap. CB, p. 96) ${ }^{53}$.

36) 1413, Fernando I, Barcelona [cfr. doc. citado como K $)^{54}$, rep. en Lf núm. 3].

37) 1438, María (lugarteniente de Alfonso V), Barcelona (Ap. CB, pp. 96 y ss. $)^{55}$.

Sentencia sobre el viejo pleito de términos y alfoces adjudicados a Puigcerdà y Llívia ${ }^{56}$, en la que se mencionan una sentencia del rey Martín en 1397, el doc. s/f del mismo en 1408 (aquí, doc. 35), así como las ya aludidas decisiones del rey Pedro sobre lo mismo.

38) 1447 (4 de febrero), María, Barcelona [cfr. doc. citado aquí como L), rep. en $L f$ núm. 8].

39) 1447 (6 de febrero), María, Perpiñán [cfr. doc. citado aquí como M), rep. en $L f$ núm. 9] .

${ }^{46}$ Fue ponente el licenciado en leyes Raimundo de Miguel, juez comisionado al efecto en el pleito entablado por la villa contra el fisco regio pidiendo restitución de pagos indebidamente exigidos por aquel. Baraut transcribe el documento anterior y éste en los núms. 26 y 27 de su Apèndix, pero no señala la relación entre ambos textos y el resumen que hace al comienzo de la sentencia no parece el más adecuado desde un punto de vista jurídico.

${ }^{47}$ Cfr. supra, punto 3 de este trabajo. CB, núm. 27 de su Apèndix.

${ }^{48}$ Cfr. supra, punto 3 de este trabajo.

${ }^{49} \mathrm{CB}$ núm. 28, anula un documento del mismo monarca (que reproduce) fechado en Cervera el 25 de abril de 1388, en el cual ampliaba el alfoz de Puigcerdà a costa del de Llívia.

${ }^{50}$ CB núm. 29.

${ }^{51}$ Cfr. supra, punto 3 de este trabajo.

${ }^{52} \mathrm{CB}$ núm. 30.

53 CB núm. 31.

${ }^{54}$ Cfr. supra, punto 3 de este trabajo.

55 CB núm. 32.

${ }^{56}$ Cfr. supra, lo dicho en la nota 43. 
40) 1447 (6 de febrero), María, Barcelona [cfr. doc. citado aquí como $\mathrm{N})$, rep. en $L f$ núm. 10].

41) 1449 (1 de febrero), María, Perpiñan [cfr. doc. citado aquí como O), rep. en $L f$ núm. 5].

42) 1449 (1 de febrero), María, Perpiñan [cfr. doc. citado aquí como P), rep. en $L f$ núm. 6].

43) 1449 (14 de febrero), María, Perpiñan [cfr. doc. citado aquí como Q), rep. en $L f$ núm. 7].

44) 1450 (1 de febrero), María, Perpiñan [cfr. doc. citado aquí como R), rep. en $L f$ núm. 4].

45) 1493, Fernando II, Perpiñán [cfr. doc. citado aquí como S), rep. en $L f$ núm. 12].

46) 1525, Carlos I, Madrid [cfr. doc. citado aquí como T), rep. en $L f$ núm. 11] .

47) 1528, Carlos I, Monzón [cfr. doc. citado aquí como U), rep. en Lf núm. 13].

48) 1529, Carlos I, Barcelona [cfr. doc. citado aquí como V), rep. en Lf núm. 14].

49) 1579, Fernando de Toledo, virrey (Felipe II), Barcelona [cfr. doc. citado aquí como W), rep. en $L f$ núm. 15 ${ }^{57}$.

50) 1585, Felipe II, Monzón, confirmación general del Derecho lliviense (Ap. CB núm. 34, pp. 100 y ss. $]^{58}$.

51) 1604, Certificación de diversos documentos regios hecha por los notarios Lorenzo Benito Puig y Montserrat Bordo [cfr. doc. citado aquí como $\mathrm{X})$, rep. en $L f$ núm. 16].

52) 1604, Arbitraje en nueve artículos, aprobado por Héctor Pignatelli, virrey de Cataluña, a propuesta de Onofre Canter, «portantveus» del gobernador general del Rosselló y La Cerdanyà, acerca de las diferencias entre diversas personas jurídicas sobre la práctica prescrita en el doc. núm. 49 supra $(A p$. CB, pp. 102 y ss. $)^{59}$.

53) 1608, Héctor Pignatelli, virrey de Cataluña (Ap. CB, pp. 105 y ss. ${ }^{60}$.

57 En el CB, núm. 33, pp. 99-100, se incluye un texto de 1580-1581 que en realidad es un acto administrativo interno de la villa en relación con la aplicación del Derecho vigente en ella, de modo que su naturaleza es diferente a la fuerza creativa propia que tienen los documentos que he ido ordenando aquí.

58 CB núm. 34.

${ }^{59} \mathrm{CB}$ núm. 35. Baraut califica a los litigantes como «estaments»; en realidad son personas jurídicas del mismo rango, pero con intereses contrapuestos.

${ }^{60} \mathrm{CB}$ núm. 36. 
54) 1613, Josep Pérez de Bonyatos, visitador del Principado [cfr. doc. citado aquí como Y), rep. en $L f$ núm. 17].

55) 1614, Francisco Hurtado de Mendoza, virrey de Cataluña ( $A p$. CB, pp. 107 y ss. $)^{61}$.

56) 1719 , duque de Berwick, en cuanto general «de los exercitos del rey». Ratificación de los usos electorales practicados bajo Carlos II (Ap. CB, p. 109) ${ }^{62}$.

A lo largo de esas cincuenta y seis disposiciones que se extienden, desde el siglo XII hasta el XVIII, y en cuyo seno se encuentra el contenido del $L f$, junto con otros materiales, cabe percibir la presencia de un vigoroso Derecho privilegiado local, dotado, en mi opinión, de tres líneas maestras en su intencionalidad. La afirmación de los términos de jurisdicción, respecto de la principal localidad competidora, Puigcerdà. El mantenimiento de los recursos necesarios para sostener el valor estratégico de la villa. La conservación secular y reñida de unos mecanismos electorales propios para la organización municipal, pero no exentos de tensiones internas.

\section{UNA HIPÓTESIS SOBRE EL SIGNIFICADO DEL CARTULARIO DE LLÍVIA}

Respecto de la última de las perspectivas que al principio he señalado como orientadoras de estas notas, cabe contemplar las valoraciones según las cuales la creación del $L f$ responde a unos criterios que desconocemos y obedece a un criterio selectivo y no exhaustivo ${ }^{63}$. Esos rasgos son estrictamente ciertos. El segundo es tan evidente que casi no era necesario apuntarlo, pero acerca del primero no es rechazable la idea de sugerir alguna hipótesis orientada algo más lejos de tales límites, demasiado obvio como dejar el tema encerrado en ellos.

Parece muy claro un primer paso. En la documentación reunida en el $L f$ (no tanto en lo que constituía la realidad lliviense en el momento de redactar ese cartulario), Llívia es presentada de forma constante e incisiva como una villa real, una comunidad dotada de personalidad jurídi-

\footnotetext{
${ }^{61} \mathrm{CB}$ núm. 37.

${ }^{62} \mathrm{CB}$ núm. 38

${ }^{63}$ C. Baraut, El Llibre ferrat..., op. cit., p. 26.
} 
ca en cuanto tal («universitas» ${ }^{64}$, «republica» ${ }^{65}$, «parrochia» ${ }^{66}$ ) establecida en un lugar concreto ( «locus» ${ }^{67}$, alternativa o acumulativamente también «villa» ${ }^{68}$; «oppidum» ${ }^{69}$, «barrio» ${ }^{70}$ ), y elevado («podium») $)^{71}$, que se gobierna por un ayuntamiento o concejo ${ }^{72}$, que extiende su influencia por un territorio circundante ( $\langle\text { baiulia }\rangle^{73}$, $\left\langle\right.$ castellania $\left.{ }^{74}\right)$, que posee plena conciencia de ser llave y seguridad de la vicaría de la Cerdanyà («clavis et firmamentum terre Ceritanie») ${ }^{75}$, a la que pertenece ${ }^{76}$, que envía mensajeros ( $«$ nuncios» ${ }^{77}$, «cónsules» ${ }^{78}$ ) elegidos entre los «probi homines»y «feminas» ${ }^{79}$ que forman el nervio jurídico de su población, a los diferentes monarcas, en defensa de su específico ordenamiento jurídico y que estaba dotada de una fortificación («castrum» ${ }^{80}$, «fortalicium» ${ }^{81}$, «castell» ${ }^{82}$ ).

De acuerdo con la tesis sostenida por la profesora Remedios Morán Martín en el amplio contexto del Derecho municipal peninsular ${ }^{83}$, no

${ }^{64}$ Es acierto de Baraut subrayar lo extremado de la condición de realengo del término lliviense (cfr. la p. 9 de su estudio). Esa impresión se realza cuando se lee en paralelo el trabajo de J. M. ${ }^{a}$ FonT I Rius, «Els origens del co-senyoriu andorrà», Pirineos, núm. 11 (1955), pp. 77 y ss. La palabra «Universitas» aparece en los puntos 2, 9, 12, 13 y 14 de la «Taula» inicial del $L f$, y en los docs. I) (reiteradamente), S), T), V), etc. Esta numeración de documentos no se refiere a la dada a las piezas por el $L f$, sino a la establecida en la ordenación que se contiene en el punto anterior de este trabajo, donde además se indica la correlación con los números del $L f$.

${ }_{65}$ «Reipublice», por ejemplo, en doc. S).

${ }^{66}$ «Parròchia», cfr. punto 10 de la «Taula» inicial y (muchas veces reiteradamente) en los docs. J), K), P), S), T), V), etc.

${ }_{67}$ «Locus» $\mathrm{O}$ «lloc» son calificaciones tan reiteradas desde la «Taula» inicial que no es preciso detallar expresamente cada caso.

68 «illa» aparece, por ejemplo, en los docs. L), N), U) y X).

${ }_{69}$ «Oppidum» en el doc. U) (reiteradamente), etc.

70 «Barrio», por ejemplo, en el doc. R).

71 «Podium», por ejemplo, en los docs. A), O), Q), etc.

72 «Concilium de Llivia», por ejemplo, en el doc. C).

73 «Bailia», en la «Taula» inicial reiteradamente y lo mismo en los docs. I), O), P) y otros muchos más.

${ }^{74}$ «Castelanía», por ejemplo, en el doc. O).

${ }_{75}$ Cfr. doc. O).

${ }^{76}$ «Locum de Llivia, situm in vicaria Ceritanie», en los docs. L) y M).

77 Ésa es la expresión que primero aparece y se mantiene continuadamente asociada a veces a «procurador», en los docs. J), K), etc.

${ }_{78}$ Algo más moderna que la anterior, por ejemplo, en los docs. T), W), etc.

79 Se hace mención a las mujeres, por ejemplo, en los docs. L) y Q), ambos de la reina María. La mención «probi homines» es reiteradísima.

80 Con «castrum» sucede lo mismo que con «locus» (cfr. supra, nota 76).

81 «Fortalicium» aparece, por ejemplo, en el doc. R).

${ }^{82} \mathrm{La}$ forma «castell» aparece en la «Taula» inicial reiteradamente.

83 R. Morán Martín, «Fueros municipales. Traza de Derecho», en J. Mattoso (dir.), Medievalista [en línea], Lisboa, IEM, disponible en http://www2.fcsh.unl.pt/iem/medievalistal. 
parece difícil ni forzado presentar el caso del $L f$ de Llívia como un ejemplo más de la configuración de derechos municipales como plasmación de la imagen que una localidad tiene de sí misma en un momento dado de su historia y de los intereses que la mueven en el momento de realizar esa configuración. Muy especialmente, los derivados de su rivalidad con otra cercana, fenómeno bien frecuente en la historia de los conflictos jurídicos de todo tiempo y en este caso patente con el secular antagonismo Puigcerdà-Llívia ${ }^{84}$, desde los años de Alfonso el Casto en siglo XII.

Es claro que el protagonista de la idea de confeccionar el $L f$ era consciente de la imagen y los intereses que acabo de describir y quiso hacer patente su conjunto en el cartulario. Quizá sea su quintaesencia la fuerza estratégica, resumen permanente de la significación de Llívia. Aun destruido para siempre el castillo por el rey de Francia Luis XI en 1479, el $L f$, recogería la caracterización «Livium oppidum» y trazaría una estampa heráldica de la ciudad al pie del monte sobre el cual se alza su castillo. La conciencia asumida acerca del fundamento geopolítico de esa personalidad es evidente y de ella se dejará constancia expresa. Así dirá la reina María, en 1449, que Llívia constituye la llave y seguridad de la tierra de La Cerdanya ${ }^{85}$ y bastante más de un siglo después, en 1579, los llamados a restaurar algunas normas de Derecho consuetudinario lliviense repetirán que su ciudad era: «la clau de la custodia de tota aquella terra» ${ }^{86}$. Siempre fue la Llívia histórica un agente jurídico, que se veía dotado con una magnitud nada despreciable, que justificaba un Derecho privilegiado local singularizado por su papel en el mantenimiento de una fortificación, «castell de gran importànctia» de donde procede una convicción: «se creu és la més antiga población de aquell comtat y en son temps és estada la principal de aquell».

No he querido ocuparme aquí de la historia de Llívia ni su territorio, ni tampoco del resumen de las particularidades de Derecho privilegiado ${ }^{87}$. Pero sí quiero concluir llamando brevemente la atención acerca de algunos aspectos que tienen que ver con las fuerzas creadoras del Derecho, a las que se hace constante apelación en los documentos reunidos en el $L f$, y los textos complementarios. Son dos: el Derecho consuetudinario ${ }^{88}$ y los

${ }^{84}$ Cfr. especialmente el doc. E) del Lf y el doc. 37 de 1438.

85 «Clavis et fundamentum terre Ceritanie», en el doc. O).

${ }^{86}$ Cfr. doc. W).

${ }^{87}$ Puede verse sobre ambos temas la síntesis elemental de C. Baraut, El Llibre ferrat..., op. cit., pp. 7 y ss., aunque a la luz de lo señalado supra, nota 7.

${ }^{88} \mathrm{Lf}$, «Taula», primo «consuetuts y usos». En los docs. A), B) у C) se mencionan «omnes consuetudines et usus dicti loci et eius baiulie». En el doc. O) se detalla la recupera- 
privilegios reales de contenido concreto, fuentes que, diplomáticamente hablando, son de una sola clase, aunque de temática variada ${ }^{89}$.

En el fondo, ambas aparecen muy influidas por la propia personalidad de la villa. Como es usual en todas partes, los privilegios que recibe están motivados siempre por la iniciativa de ella y en la mentalidad de los solicitantes se amalgama la percepción de lo significativo de su función pública, con el deseo de infundir a todo el Derecho local la imagen de una respetable antigüedad y práctica consuetudinaria. Las apelaciones a lo acostumbrado desde antiguo son muy frecuentes, pero alcanzarán ciertas cotas ascendentes desde $1337^{90}$, se mantendrán en $1342^{91}$ y $1447^{92}$ y alcanzarán su apogeo en 1579. En esta ocasión se trata de lo que se presenta como una recuperación del Derecho consuetudinario, hecha por «los bòmens de la dita vila», quienes ${ }^{93}$

«hagut acord $i$ entre ells y entre altres persones de govern y de speriéntia, an collegit dites consuetuts e bonès practiques en dita vila observades».

Se establecieron así los catorce capítulos relativos al orden y modo con que se ha de erigir del Concejo general, su comisión delegada; el régimen de los cónsules (su nominación, requisitos, distintivos y distribución entre Llívia, Sereja y Gurguja) y demás cargos y oficios municipales y el orden a seguir para su sorteo; las designaciones de notario, jurados, síndico y otras disposiciones generales relativas al desempeño de los cargos; la forma de realizar los sorteos; la prestación de juramento y la obligatoriedad de los cargos. Y no es de olvidar tampoco que todo ello se realizó en el tiempo de Felipe II y por uno de sus colaboradores más sólidos en las directrices de su gobierno. No es casual que no sólo en Llívia, sino también en Vizcaya, en Flandes y en América, se tratase entonces de investigar y restaurar normas y prácticas que los naturales del territorio entendían como fruto y muestra de su Derecho consuetudinario.

ción de ese Derecho consuetudinario perdido: «collegit dites consuetuts e bones pràctiques en dita vila observades».

${ }^{89}$ C. Baraut, El Llibre ferrat..., op. cit., p. 17, habla de «Classes de privilegis», pero aquí el autor se refiere a los temas contemplados. Las calificaciones de «clases» o «tipos» en la técnica diplomática son referencias puramente formales o externas, que de suyo son ajenas al contenido material de los textos y no conciernen a las temáticas de los documentos. Cfr. supra, nota 7.

${ }^{90}$ Cfr. doc. B).

${ }^{91}$ Cfr. doc. D).

92 Cfr. doc. N).

${ }_{93}$ Cfr. doc. W). 